\section{A new endoscopic treatment method for a symptomatic duodenal duplication cyst}
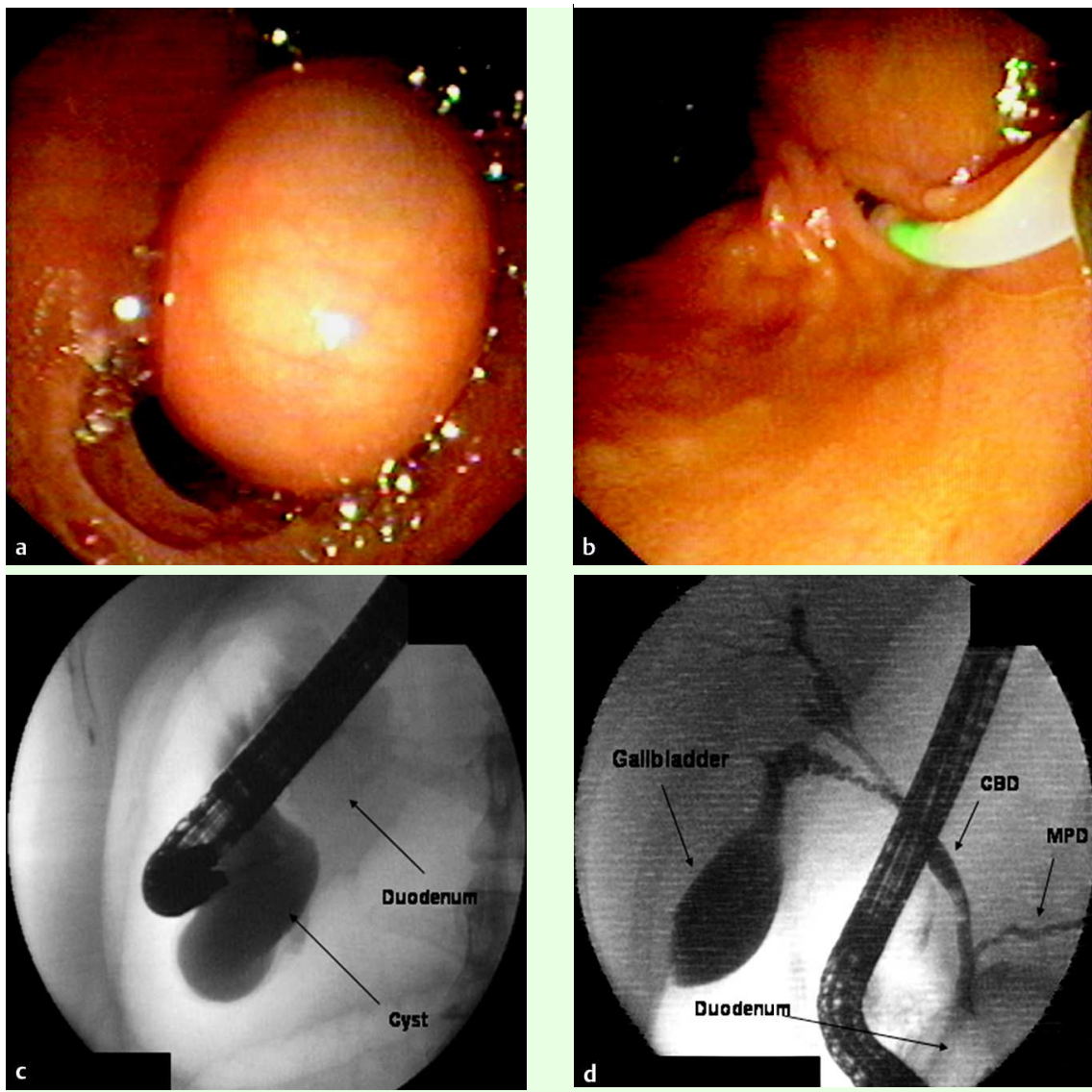

Fig. 1 Duodenoscopy revealed a cystic polypoid lesion protruding inside the duodenal lumen. b The orifice of the papilla was found to be at the back side of the cystic lesion allowing cannulation. c Opacification of the cyst. Note the absence of the communication with the common bile duct. d The gallbladder, common bile duct (CBD) and the main pancreatic duct (MPD) were of normal size and shape.

An 18-year-old woman was referred to our clinic for endoscopic retrograde cholangiopancreatography (ERCP) because of a history of recurrent abdominal pain and a previous episode of acute pancreatitis. No etiology was found except a duodenal cystic polypoid lesion detected at computed tomography. ERCP revealed a cystic lesion with a $3 \times 2 \mathrm{~cm}$ diameter ( $\mathrm{Fig} .1 \mathrm{a}$ ), and the orifice of the papilla to be at the back side of the cystic lesion ( Fig. 1b). After the cannulation had been performed, the cystic lesion ( $\bullet$ Fig. 1c), the common bile duct, and the pancreatic duct ( $\bullet$ Fig. 1 d) were opacified through the common channel. The gallbladder, common bile duct, and pancreatic duct were of normal size and shape. As the cystic lesion showed no communication with the common bile duct, a diagnosis of a duodenal duplication cyst (DDC) was established rather than a choledochocele.

An incision was made with a needle-knife sphincterotome (Boston Scientific Microvasive, Indiana, USA) on the anterior portion of the cyst. After the cyst was cannulated, a guide wire was sent into the cystic cavity. Thereafter, dilation with an 8-mm diameter balloon ( $\bullet$ Fig. 2 ) and a consecutive plastic stent implantation (10-Fr double-pigtail) were performed. Drainage of a whitish viscous secretion, but not the bile, was observed through the pigtail stent. The pigtail stent was endoscopically removed 1 month later, and the DDC cavity was found to be totally collapsed ( $\odot$ Fig.3). Four months after

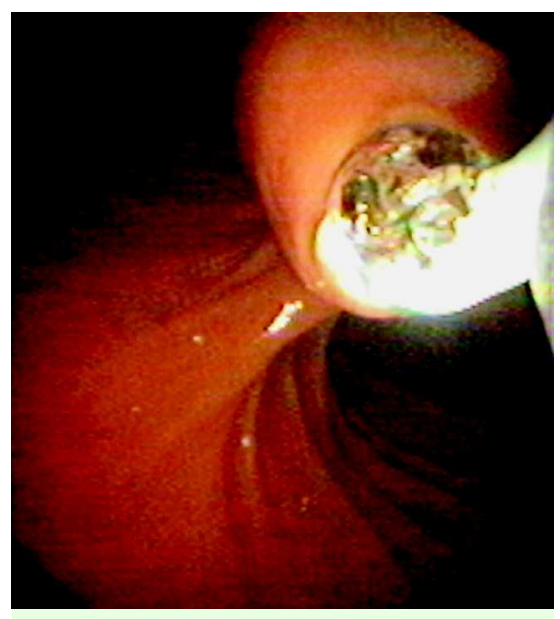

Fig. 2 After an incision on the cyst, balloon dilation through the guide wire was performed. Thereafter, a pigtail stent was implanted.

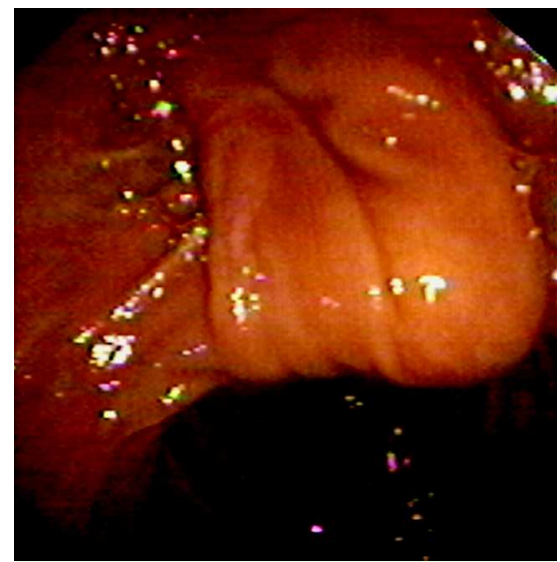

Fig. 3 The cyst cavity was found to be totally collapsed after 1 month.

discharge, the patient was well and symptom free.

Although surgically complete resection of the DDC is the standard therapy, few endoscopic therapies have also been reported. Use of the endoscopic needle-knife and sphincterotome to open the cyst into the duodenum [1] and endoscopic partial resection of the cyst $[2,3]$ are the favored endoscopic methods. This is the first report of a DDC that has been successfully treated with needle-knife sphincterotome incision, balloon dilation, and a plastic stent implantation.

\section{Endoscopy_UCTN_Code_CPL_1AK_2AJ}

\section{F. Tekin, O. Ozutemiz, G. Ersoz, o. Tekesin}

Department of Gastroenterology, Ege University Medical School, Izmir, Turkey 
References

1 Vandenbroucke F, Dagenais $M$, Letourneau $R$ et al. Endoscopic treatment of a duodenal duplication cyst. Endoscopy 2005; 37: 601

2 Wada S, Higashizawa T, Tamada K et al. Endoscopic partial resection of a duodenal duplication cyst. Endoscopy 2001; 33: $808-$ 810

3 Antaki F, Tringali A, Deprez P et al. A case series of symptomatic intraluminal duodenal duplication cysts: presentation, endoscopic therapy, and long-term outcome. Gastrointest Endosc 2008; 67: 163 - 168
Bibliography

DOI $10.1055 / s-2008-1077337$

Endoscopy 2009; 41: E32 -E33

(c) Georg Thieme Verlag KG Stuttgart · New York . ISSN 0013-726X
Corresponding author

\section{F. Tekin, MD}

Ege Universitesi Tip Fakultesi

Gastroenteroloji Bilim Dali

Bornova 35100

Izmir

Turkey

Fax: +90-232-3427764

drtekinfatih@yahoo.com 